\title{
Subgroup analysis of the extended efficacy and safety of low-dose methoxyflurane analgesia in adolescent patients from the STOP! study with acute trauma pain
}

F. Coffey', M. Lomax²

'Emergency Department, Nottingham University Hospitals NHS Trust, Nottingham, UK

${ }^{2}$ Biostatistics \& Clinical Data Science, Mundipharma Research Limited, Cambridge, UK

\section{BACKGROUND AND GOAL OF STUDY}

Low-dose methoxyflurane, self-administered by the patient via a handheld inhaler (Penthrox ${ }^{\oplus}, 3 \mathrm{~mL}$ dose) is a fast-acting non-narcotic analgesic agent that has been used in Australia and New Zealand for over 40 years. Despite a large volume of published literature supporting the efficacy and safety of methoxyflurane at analgesic concentrations ${ }^{1}$, previous studies have been mostly observational and uncontrolled.

The STOP! study ${ }^{2,3}$ was a large double-blind, randomised, placebo-controlled UK study that investigated the efficacy and safety of low-dose methoxyflurane analgesia administered via the Penthrox ${ }^{\circledR}$ inhaler for the treatment of moderate to severe trauma pain in the Emergency Department (ED).

The reduction in visual analogue scale (VAS) pain intensity in the first 20 minutes after the start of treatment has previously been reported ${ }^{2,3}$. We present a post hoc analysis of the change from baseline in VAS pain intensity beyond this time point, and safety results, in a subgroup of adolescent patients aged 2 to 17 years $(\mathrm{N}=95)$.

\section{MATERIAL AND METHODS} (and mised (at triage) in a 1.1 ratio to receive methoxyflurane (up to $2 \times 3 \mathrm{~mL}$ ) or placebo (normal saline) each via a Penthrox ${ }^{\circledR}$ inhaler.

- Thantain the bilnd, a drop of methoxyflurane was placed on the outside of the primed inhalers so that the smell between active and placebo treatments was indistinguishable.

-

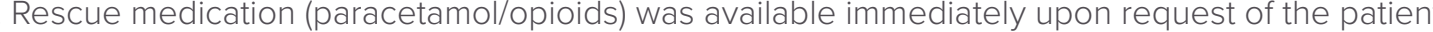

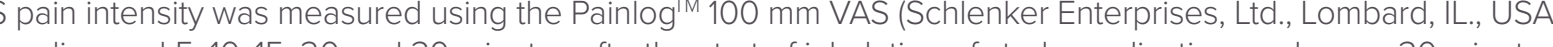
thaseline and 5, 10, 15, 20 and 30 minutes afterthe start of inhalation of study medication, and every 30 minutes (he

- The primary efficacy endpoint was the change in VAS pain intensity score from baseline over the 20 minutes after the start of study medication inhalation. We present change from baseline in VAS pain intensity scores beyond 20 minutes after the start of treatment for the adolescent subgroup. RESULTS AND DISCUSSION

Patient Characteristics

- The adolescent subgroup included 67 male patients and 28 female patients with a mean age of 14 years. categorised as "other" (predominantly sprains, soft tissue injury and muscular pain).

\section{Table 1. Injury Details (Adolescent Subgroup)}

\begin{tabular}{|c|c|c|c|c|}
\hline \multicolumn{2}{|c|}{ NUMBER (\%) OF PATIENTS } & $\begin{array}{l}\text { METHOXYFLURANE } \\
(\mathrm{N}=47)\end{array}$ & $\begin{array}{l}\text { PLACEBO } \\
(\mathrm{N}=48)\end{array}$ & $\begin{array}{l}\text { TOTAL } \\
(\mathrm{N}=95)\end{array}$ \\
\hline \multirow{7}{*}{ Injury site } & Back & $1(2.1)$ & $1(2.1)$ & $2(2.1)$ \\
\hline & Face & $2(4.3)$ & $1(2.1)$ & $3(3.2)$ \\
\hline & Left lower limb & $5(10.6)$ & $9(18.8)$ & $14(14.7)$ \\
\hline & Left upper limb & $13(27.7)$ & $8(16.7)$ & $21(22.1)$ \\
\hline & Other & $7(14.9)$ & $4(8.3)$ & $11(11.6)$ \\
\hline & Right lower limb & $6(12.8)$ & $11(22.9)$ & $17(17.9)$ \\
\hline & Right upper limb & $13(27.7)$ & $14(29.2)$ & $27(28.4)$ \\
\hline \multirow[t]{6}{*}{ Injury type } & Contusion & 9 (19.1) & $6(12.5)$ & $15(15.8)$ \\
\hline & Dislocation & $1(2.1)$ & $1(2.1)$ & $2(2.1)$ \\
\hline & Fracture & $11(23.4)$ & $11(22.9)$ & $22(23.2)$ \\
\hline & Injury due to foreign body & $1(2.1)$ & - & $1(1.1)$ \\
\hline & Laceration & $1(2.1)$ & $1(2.1)$ & $2(2.1)$ \\
\hline & Other $^{+}$ & $24(51.1)$ & $29(60.4)$ & $53(55.8)$ \\
\hline
\end{tabular}

Note: First injury details are presented Only one patient had more than muscular

- Baseline pain severity is presented in Table 2. Almost half of the patients (46\%) in the adolescent subgroup had severe pain (NRS score of 7) at baseline. All remaining patients had moderate pain at baseline (NRS

Table 2 Numeric Rating Scale (NRS) Pain Score at Baseline (Adolescent Subgroup)

\begin{tabular}{|c|c|c|c|}
\hline $\begin{array}{c}\text { BASELINE NRS } \\
\text { PAIN SCORE }\end{array}$ & $\begin{array}{c}\text { METHOXYFLURANE (N=47) } \\
\mathbf{n}(\%)\end{array}$ & $\begin{array}{c}\text { PLACEBO (N=48) } \\
\mathbf{n}(\%)\end{array}$ & $\begin{array}{c}\text { TOTAL (N=95) } \\
\mathbf{n}(\%)\end{array}$ \\
\hline 4 & $4(8.5)$ & $4(8.3)$ & $8(8.4)$ \\
\hline 5 & $7(14.9)$ & $14(29.2)$ & $21(22.1)$ \\
\hline 7 & $15(31.9)$ & $7(14.6)$ & $22(23.2)$ \\
\hline
\end{tabular}

- Mean ( \pm standard deviation) VAS pain scores at baseline were $61.7 \pm 16.56 \mathrm{~mm}$ in the methoxyflurane group and $61.0 \pm 13.33 \mathrm{~mm}$ in the placebo group.

\section{VAS pain intensity beyond 20 minutes}

Mean change in VAS pain intensity from baseline over the first 20 minutes was significantly greater for the subgroup ${ }^{3}$ )

The decrease in VAS pain intensity achieved with methoxyflurane over the first 20 minutes was maintained minutes after the start of treatme

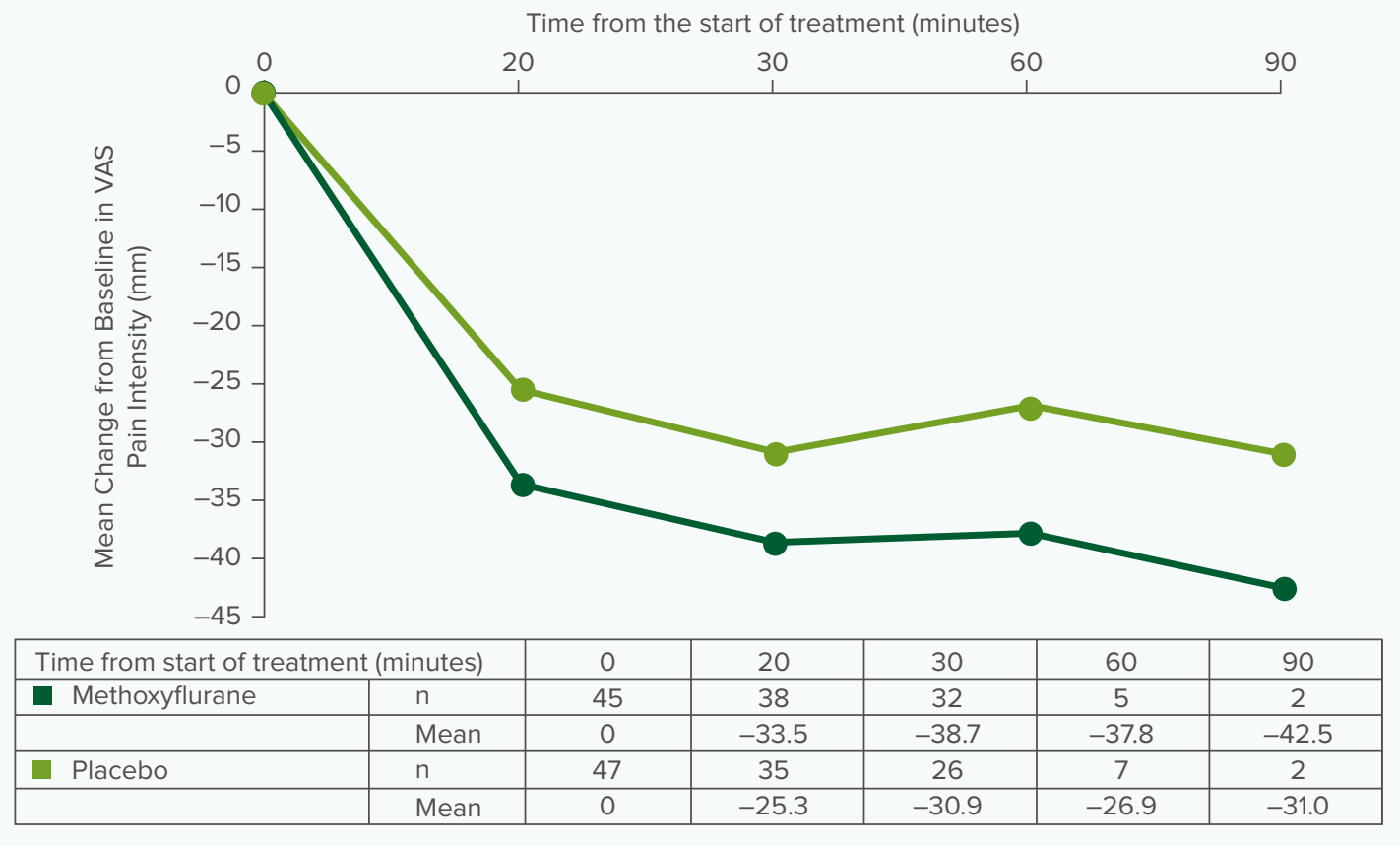

Pain scores taken after initiation of rescue medication
planned DD procedure are excluded from the analysis.
Data are only presented for time points where n22.

Figure 1. Mean Change from Baseline in Visu

- The number of patients with avalable VAS data decreased at each time point which was mainly due to

Safety

TEAE rates for the adolescent subgroup are presented in Table 3 . Fifty-five AEs were reported by 24 patients

(51\%) in the methoxyflurane group and 35 AE

\begin{tabular}{|l|c|c|}
\hline NUMBER (\%) OF PATIENTS & $\begin{array}{c}\text { METHOXYFLURANE } \\
(\mathbf{N}=\mathbf{4 7 )}\end{array}$ & $\begin{array}{c}\text { PLACEBO } \\
(\mathbf{N}=\mathbf{4 8})\end{array}$ \\
\hline TEAEs & $24(51.1)$ & $20(41.7)$ \\
\hline Treatment-related TEAEs & $11(23.4)$ & $5(10.4)$ \\
\hline Serious TEAEs & 0 & 0 \\
\hline TEAEs leading to withdrawal & $2(4.3)$ & $2(4.2)$ \\
\hline TEAEs reported by 23 patients in either treatment group & $12(25.5)$ & $11(22.9)$ \\
\hline Headache & $7(14.9)$ & $1(2.1)$ \\
\hline Dizziness & $3(6.4)$ & 0 \\
\hline Somnolence & 0 & $3(6.3)$ \\
\hline Influenza like illness & & \\
\hline
\end{tabular}

Influenza like illness

- The TEAEs reported were generally mild and transient in nature.

- The most commonly reported TEAEs were headache, dizziness, somnolence and influenza type illness. Dizziness and somnolence were more common in methoxyflurane-treated patients, influenza type illness was more common in placebo-treated patients and headache was reported at a similar frequency in both groups. Two patients (4\%) in each treatment group withdrew due to a TEAE:

- Methoxyflurane group: one patient due to feeling dizzy and one patient due to light headedness, bad

taste and burning in his mouth

Placebo group: one patient due to feeling light headed and nausea and one patient due to loss of

consciousness lasting for $\sim 1$ minute.

CONCLUSION

- These results show that the reduction in pain intensity with low-dose methoxyflurane analgesia is maintained These results show that the reduction in pain intensity with low-dose
for the duration of use in adolescent patients with acute trauma pain.
ACKNOWLEDGEMENTS AND DISCLOSURES

The study was funded by Medical Developments International (MDI) Limited. Karen Mower (Scientific Editorial) provided medica Frank Coffey was paid travel and subsistence expenses by MDI for one investigator's meeting. Mark Lomax is an employee of This work as a whole or any substantial part of it must not be copied, further issued to the public or reproduced in any material form without prior written consent of the copyright owner. 